\title{
Photochemistry of para substituted benzanilides in solution: Preparative and mechanistic studies
}

\author{
Valentín Lucena $^{1,2} \cdot$ Matías I. Quindt $^{1,2} \cdot$ Stefano Crespi ${ }^{3} \cdot$ Sergio M. Bonesi ${ }^{1,2}(\mathbb{D}$
}

Received: 13 September 2021 / Accepted: 28 November 2021 / Published online: 23 January 2022

(c) The Author(s), under exclusive licence to European Photochemistry Association, European Society for Photobiology 2021

\begin{abstract}
Preparative and mechanistic studies on the photochemical reaction of a series of p-substituted benzanilides in polar and nonpolar solvents have been carried out. The aim of this work is mainly focused to show whether the reaction solvent and the electronic effects of the substituents affect the product distribution, the chemical yields and the rate of formation of the 5-substituted-2-aminobenzophenone derivatives. Application of the Hammett linear free energy relationship (LFER) on the rate of formation of 2-aminobenzophenone derivatives, on the lower energy band of the UV-visible absorption spectra of the benzanilides and 5-substituted-2-aminobenzophenone derivatives allows a satisfactory quantification of the substituent effects. Furthermore, the solvent effect was also analyzed on the photoreaction by means of the Reichardt's solvent parameter $\left(\mathrm{E}_{\mathrm{T}}(30)\right.$. Finally, (TD-) DFT calculations have been carried out to support the trends observed experimentally.
\end{abstract}

\section{Graphical abstract}

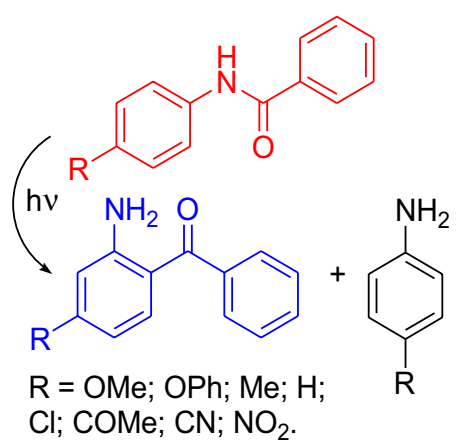

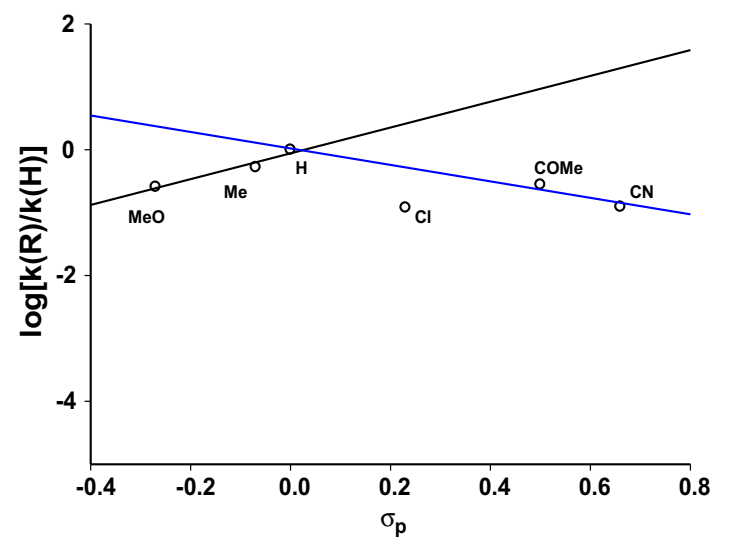

Valentín Lucena and Matías I. Quindt contributed equally to this work.

Sergio M. Bonesi

smbonesi@qo.fcen.uba.ar

1 Departamento de Química Orgánica, Facultad de Ciencias Exactas y Naturales, Universidad de Buenos Aires,

C1428EGA Buenos Aires, Argentina

2 Centro de Investigaciones en Hidratos de Carbono (CIHIDECAR), CONICET-Universidad de Buenos Aires, C1428EGA Buenos Aires, Argentina

3 Stratingh Institute for Chemistry, University of Groningen, Nijenborgh 4, 9747AG Groningen, The Netherlands

\section{Introduction}

The photo-Fries rearrangement is a useful photoreaction that leads to the facile preparation of 2-hydroxy- as well as 2-aminobenzophenones [1-3] Anderson and Reese discovered this photochemical transformation of aryl esters (or amides) in 1960 [4]. It is well-established that this process involves a homolytic cleavage of the $\mathrm{C}-\mathrm{X}$ bond $(X=\mathrm{O} ; \mathrm{N}$, see Fig. 1) from its singlet excited state and consequently generates radical pairs entrapped in a solvent cage. Recombination of such radicals through [1,3], [1, 5]-migration mainly affords the $\mathrm{o}$ - and p-rearranged photoproducts while 
Fig. 1 The photo-Fries rearrangement: competitive pathways

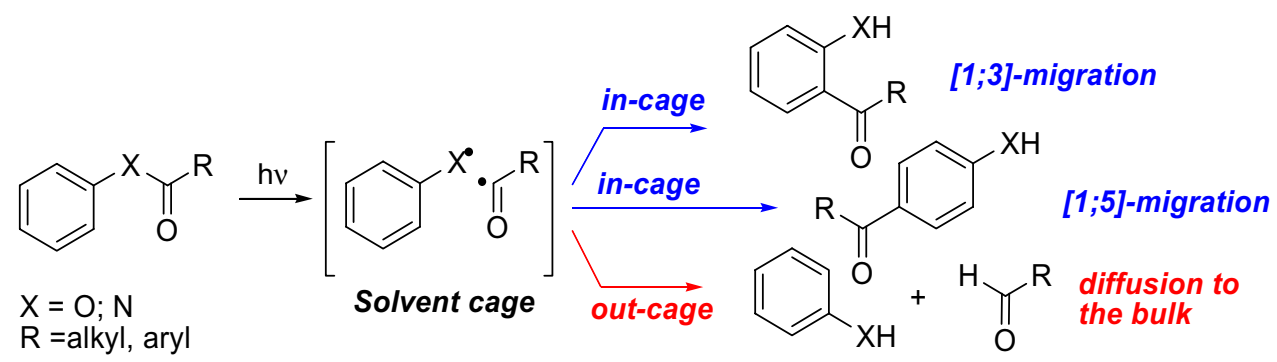

radical escape from the solvent cage provides the phenols (or anilines), as depicted in Fig. 1 [1-3].

Pioneering studies on the photo-Fries rearrangement of acetanilides and benzamide are known since 1963 and were developed by Elad, Rao and Steinberg [5, 6]. Latter, Shizuka and co-workers have studied in depth the photo-Fries rearrangement of acetanilide in term of photoexcited state, product distribution, and proposal of the reaction mechanism $[7,8]$. Furthermore, the photochemistry of benzanilide and p-methylbenzanilide has been examined in detail at various excitation wavelengths, in different solvents and in the absence and presence of molecular oxygen, particularly, in terms of quantum yields of photoproduct formation [9]. Lee and co-workers have studied the photochemistry of benzanilide and substituted 2-chloro-, 2-bromo- and 2-methoxybenzanilides [10]. Although direct irradiation of benzanilide gave the expected photo-Fries rearrangement reaction, the other 2-substituted benzanilides provided the substituted phenanthridone derivatives due to an efficient photoinduced $6 \pi$-electrocyclization reaction marking a change in the reactivity of benzanilides depending on the substitution pattern. The direct irradiation $(254 \mathrm{~nm})$ of $\mathrm{N}$-acetyl diphenylamide and heteroaryl amides such as $\mathrm{N}$-acetyl- and $\mathrm{N}$-benzoylcarbazoles have been carried out in different solvents and the photo-Fries rearrangement reaction occurred with noticeable efficiency [11-13]. Likewise, the photochemistry of acetanilides and benzanilides has been studied in water in the presence of $\beta$-cyclodextrin and surfactants, respectively, showing a noticeable product selectivity [14-16].

The photophysical properties of benzanilides have been intensively studied. The dual fluorescence emission in non-polar and polar solvents [18-29] was attributed to the population of local excited state (LE) affording a short wavelength emission, while the nature of the state that originates a longer wavelength emission was subject of debate. Kasha and co-workers assigned the blue-green fluorescence emission to the imidol tautomer of benzanilide [30]. Latter, it was found that several benzanilide derivatives display anomalous long-wavelength fluorescence due to the twisted amide bond (TICT states), which are considerably stabilized by charge delocalization onto the aniline moiety and the phenyl group [19]. Further, the spectroscopic behavior of six $N$-arylbenzamides has been deeply studied in methylcyclohexane toluene solution and in rigid glass matrices concluding that the photophysical behavior depends on the interactions between benzamide and aminoarene moieties of the molecules [20-22]. Likewise, the luminescence spectroscopy of p-methylbenzanilide, $N$-methyl-p-methylbenzanilide, p-nitrobenzanilides and $N$-benzylbenzanilide in different conditions has also been studied. Steady-state and time-resolved spectroscopy demonstrated that the relative intensities depended on the solvent polarity [23-25].

More recently, a series of p-dimethylaminobenzanilides with para or meta substituents at the amido aniline were prepared to analyze the substituent effect on the fluorescence emission [26, 27]. A dual fluorescence emission was observed, and surprisingly, it was found that the TICT emission displayed an inverted parabolic dependence shifting when correlated with Hammett substituent parameter $(\sigma)$. This study suggested that the anilino group could be a stronger electron donor than an aliphatic amino group. Consequently, a series of para substituted benzanilides modified exclusively on the aniline moiety has been studied. Dual fluorescence emission was detected, showing very low fluorescence emission quantum yields $\left(\Phi_{\mathrm{f}}\right)$ [27]. On the other hand, $N$-benzoylnaphthalenes displayed a noticeable substituent effect of the TICT fluorescence band, providing a linear Hammett correlation [28, 29]. Furthermore, the energy of the charge transfer band of such amides correlated nicely with the reduction potential.

Although the photophysical properties of benzanilide derivatives were the subject of extensive studies, their photochemistry was scarcely analyzed [1-3] Herein, we describe the results obtained on the direct irradiation of several para-substituted benzanilides in homogeneous media under steady-state conditions. We analyzed the solvent and substituent effects on the photoreaction applying the Hammett correlation on the reaction rates and the energies of the absorption bands of p-substituted benzanilides. Computational analysis via DFT and TD-DFT supported the presence of substituent and solvent effects at the ground and excited state supporting the linear correlations measured experimentally. 
Scheme 1 The photo-Fries rearrangement reaction of p-substituted benzanilides

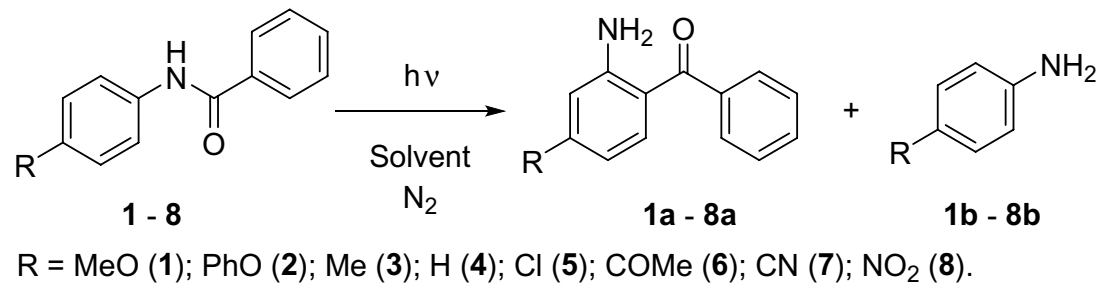

\section{Results}

The photo-Fries rearrangement reaction of 4-substituted benzanilides. We systematically carried out the direct irradiation $(254 \mathrm{~nm})$ under inert atmosphere of several benzanilides substituted with different electron-donor and electron-acceptor groups in para position. The photo-Fries rearrangement reaction (see Scheme 1) of these compounds was followed by UV-vis spectroscopy. The variation of the UV-visible absorption spectra with irradiation time show the presence of three isosbestic points located at ca. 220, 250 and $300 \mathrm{~nm}$ (see Fig. 2). This behavior shows that benzanilides 1-8 are mainly converted photochemically into the corresponding benzophenones (1a-8a). The variation of the UV-visible absorption spectra with irradiation time of benzamides $(\mathbf{1}-\mathbf{8})$ in all the solvents used in this study are presented in Figures S1-S8 (see ESI).

The photolyzed reaction mixture obtained after irradiation of benzanilides $(\mathbf{1}-\mathbf{8})$ during $24 \mathrm{~h}$ with UV light was also analyzed by gas chromatography leading to the determination of the conversion of the chemical yields of the photoproducts (see Table 1). We kept the photo-conversion of the benzanilide derivatives lower than $20 \%$ to avoid possible secondary photochemical reactions. As is apparent from the result, $\mathbf{1 a}-\mathbf{8 a}$ were formed in moderate yields, along with the corresponding p-substituted anilines $(\mathbf{1 b}-\mathbf{8 b})$. The yields of benzophenones did not depend markedly on the polarity of the solvent. Irradiation of benzanildes $\mathbf{1}$ and $\mathbf{2}$ in acetonitrile were also irradiated with $310 \mathrm{~nm}$ light. The photoreaction proceeded smoothly, halving the yields of benzophenones 1a and 2a, reflecting that the photoreaction is faster with $254 \mathrm{~nm}$ light than with $310 \mathrm{~nm}$ (for a quantitative treatment of the quantum yields of reactions, vide infra).

$p$-Nitrobenzanilide $\mathbf{8}$ shows a distinct photochemical behavior when compared with the other benzanilides. Indeed, benzophenone $\mathbf{8 a}$ was obtained upon irradiation of amide $\mathbf{8}$ in methanol at $254 \mathrm{~nm}$ in $16 \%$ yield, however, no photoreaction was observed in acetonitrile or benzene. Furthermore, irradiation of benzanilide $\mathbf{8}$ in acetonitrile at $310 \mathrm{~nm}$ provided only $4 \%$ of benzophenone $\mathbf{8 a}$. No formation of the p-nitroaniline (8b) was observed upon irradiation of compound $\mathbf{8}$ with both light sources in all the solvents studied. The distinct photochemical behavior of benzanilide $\mathbf{8}$ was attributed to the presence of the nitro group attached to the phenyl moiety that favors the singlet to the triplet change of multiplicity in the excited state through intersystem crossing due to spin-orbit coupling [30]. The $\phi_{\text {ISC }}$ quantum yields of aromatic compounds bearing a nitro group are higher than 0.50 , demonstrating that the triplet state is populated efficiently [31, 32]. Therefore, it is expected that for compound $\mathbf{8}$ the intersystem crossing pathway competes with the photo-Fries reaction, depopulating the singlet excited state in favor of the unreactive triplet $[1,33]$. Similar photochemical behavior has been observed previously in nitro substituted acetanilides[17] and benzoates [34].

The reaction quantum yields $\left(\phi_{R}\right)$ of benzanilides $\mathbf{1 - 8}$ were measured in all the solvents studied at both excitation wavelengths (254 and $310 \mathrm{~nm}$, see Table 2). The data collected in the table indicates that the photo-Fries rearrangement of benzanilides proceeds efficiently in hexane while in polar solvents such as methanol and acetonitrile the photoreaction proceeds less smoothly. The $\phi_{\mathrm{R}}$ values measured in polar solvents diminish by one order of magnitude compared with those measured in hexane. The trend observed for polar solvents was also observed in benzanilides irradiated with UV light of $310 \mathrm{~nm}$. The photophysical behavior of benzanilides in polar and nonpolar solvents has been extensively studied and it is known that a significant charge separation between the benzamido group ( $\mathrm{PhCONH}-$ ) and the substituents in para position ( $\mathbf{R}-\mathrm{Ph}-)$ occurs favoring a twisted amide bond excited state (TICT states) [18-27]. Polar solvents promote the stabilization of the TICT excited state, favoring the deactivation of such species through fluorescence emission and radiationless pathways and preventing any photochemical reaction. On the other hand, this interesting behavior does not occur efficiently when the solvent is nonpolar (e.g. hexane). In this case the photoFries rearrangement proceeds smoothly, showing $\phi_{R}$ values higher than those measured in polar solvents (see Table 2). Therefore, it is evident that there is an excellent correlation between the literature on the photophysical properties of benzanilides and the result obtained from the reaction quantum yields $\left(\phi_{\mathrm{R}}\right)$. The polarity effect can be appreciated optimizing the S1 excited state of 1-8 at the TD- $\omega$ B97X-D/ def2-SVP level in gas phase or using acetonitrile as implicit solvent (see Figure S20 and S21). In the gas phase only the strong electron-donating groups $\mathrm{MeO}$ and $\mathrm{PhO}$ promote the 

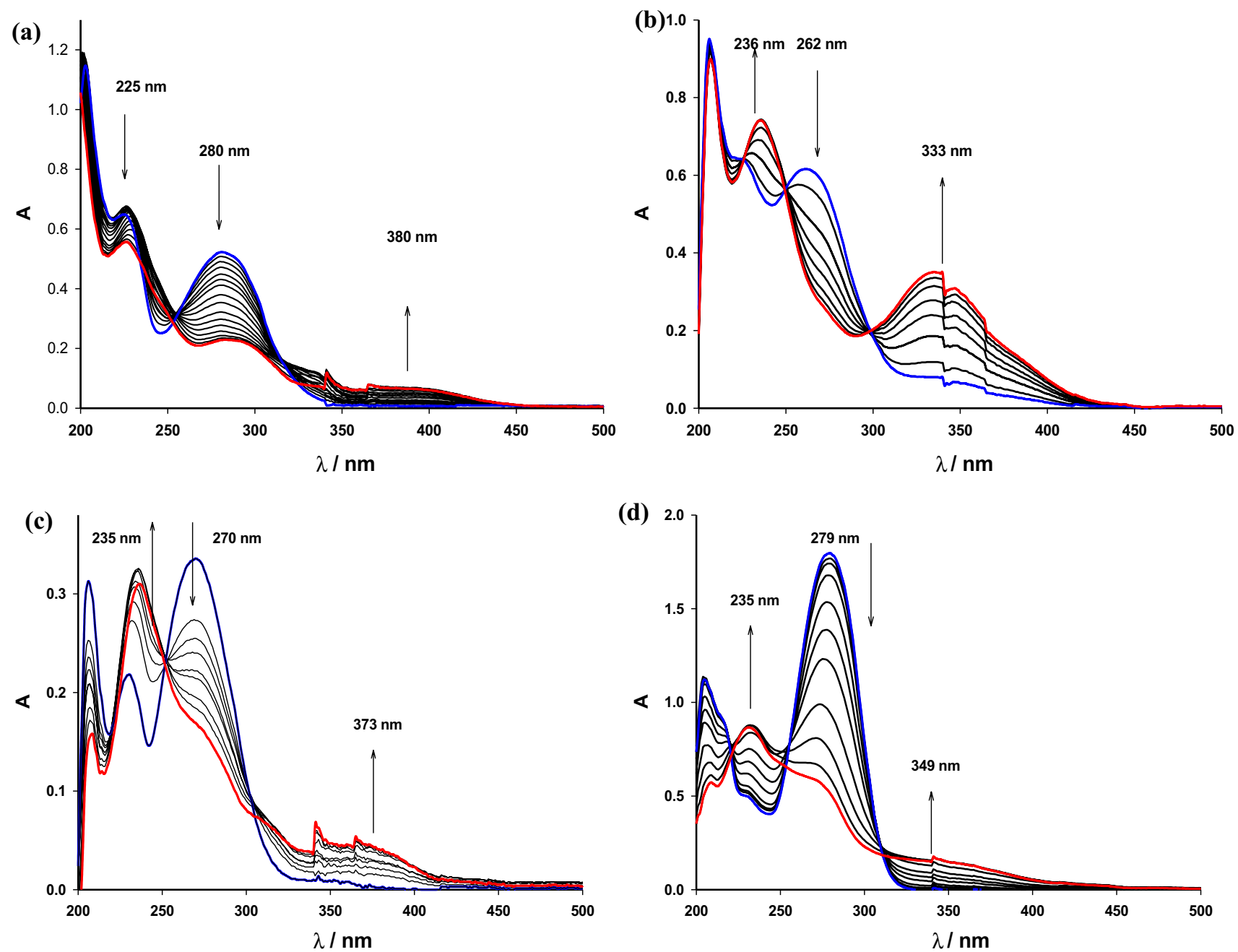

Fig. 2 (a) p-Methoxybenzanilide (1) in Hexane at $254 \mathrm{~nm}$. (b) Benzanilide (4) in $\mathrm{MeOH}$ at $254 \mathrm{~nm}$. (c) p-Chlorobenzanilide (5) in hexane at $254 \mathrm{~nm}$. (d) p-Cyanobenzanilide(7) in $\mathrm{MeCN}$ at $310 \mathrm{~nm}$. Blue line: zero time; red line: infinite time

formation of a TICT state, while only $\mathrm{NO}_{2}, \mathrm{CN}$ and $\mathrm{COMe}$ maintain a planar $\mathrm{S} 1$ geometry in acetonitrile.

Effect of Substituents and nature of the solvent on both the absorption spectra and the photoreaction rate constants. The absorption spectra of benzanilides display two characteristic bands. The main absorption band is centered between 255 and $287 \mathrm{~nm}$, depending on the polarity of the solvent and the nature of the substituent (see Table 3). Indeed, a slight hypsochromic shift of the main absorption band of benzanilide 1-5 was observed as the polarity of the solvent increases moving from hexane toward methanol. However, we recorded a bathochromic shift for benzanilides bearing electron-acceptor substituents $(\mathbf{6}-\mathbf{8})$ as the polarity of the solvent increases.

Applying the Hammett correlation on the electronic transition energy of the p-substituted benzanilides [36, 37], we confirmed that the spectroscopic behavior in this class also depends on the nature of the solvent. We correlated the energies of the lower absorption band measured in hexane using the Hammett substituent constants $\sigma$ [38], obtaining a linear correlation with a slope $(\sigma)$ of +0.39 [Fig. 3(a)]. Consequently, the electron-withdrawing substituents promote a hypsochromic shift of the absorption band. On the other hand, the energies of the lower absorption band measured in polar solvents such as acetonitrile and methanol were found to correlate nicely with the Hammett substituent constants $\sigma$ but affording two linear relationships with opposite slopes, as can be seen in Fig. 3(b). This surprising behavior showing a clear bell shape was not observed when the solvent was hexane and deserves additional comments.

The linear Hammett correlation that only involves electron-donor substituents (blue dash line in Fig. 3(b)) provides a $\rho$ value of $+0.65\left(R^{2}>0.80\right)$ whereas the linear correlation involving only electron-acceptor substituents [black solid line in Fig. 3(b)] gives a slope value of $-0.88\left(R^{2}>0.75\right)$. 
Table 1 Yields of photoproducts measured in different solvents ${ }^{\mathrm{a}}$

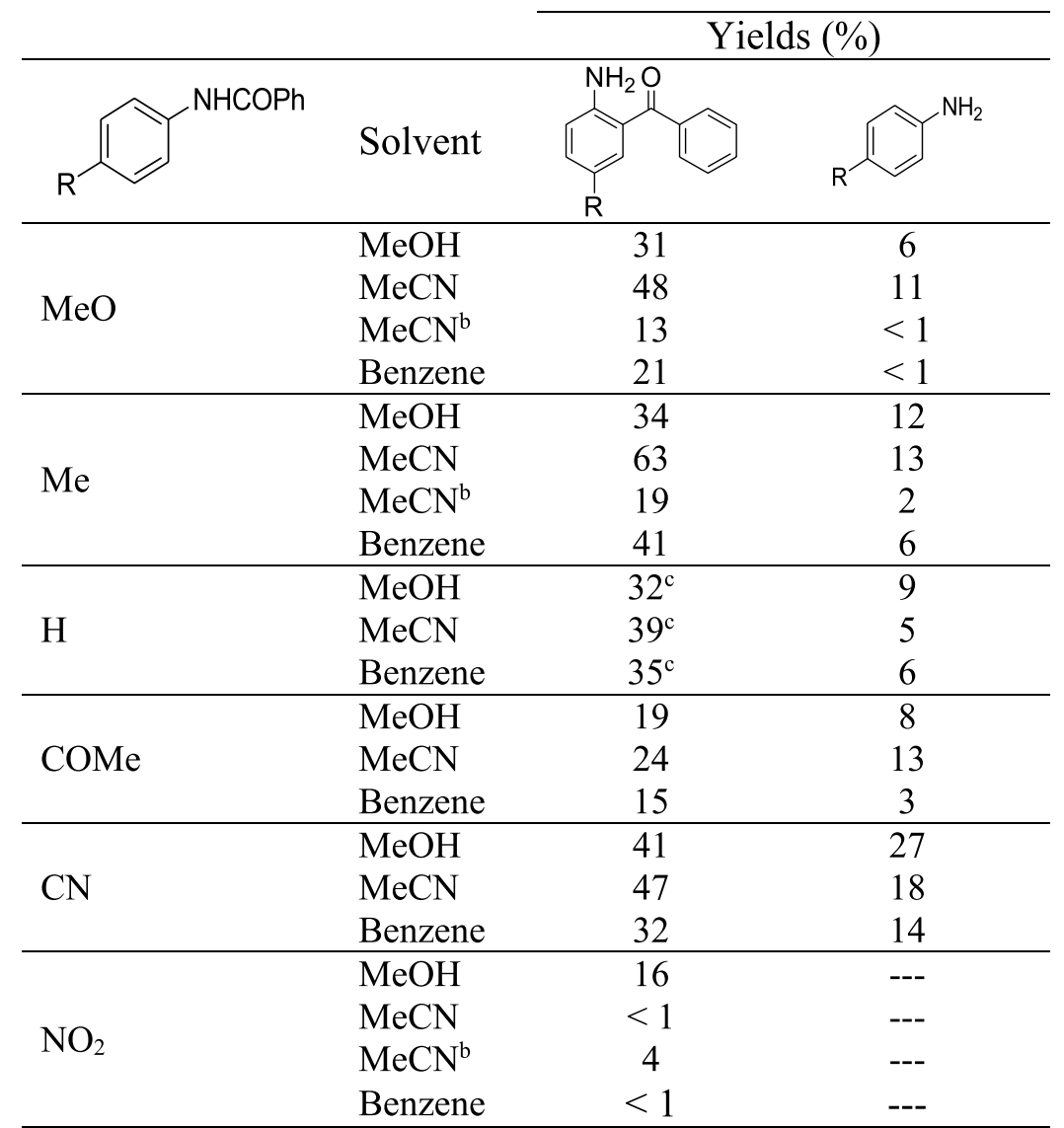

${ }^{a}$ Yield of photoproducts determined by GC of the reaction mixture. Preparative irradiation carried out with light of $254 \mathrm{~nm}$. Concentration of 4-substituted benzanilides: $5.0 \times 10^{-3} \mathrm{M} .{ }^{b} \lambda_{\text {exc }}=310 \mathrm{~nm}$. ${ }^{\mathrm{c}} 4$-Aminobenzophenone is also formed in $8-10 \%$.

Table 2 Reaction quantum yield $\left(\phi_{\mathrm{R}}\right)$ measured in different solvents ${ }^{\mathrm{a}}$

\begin{tabular}{cccccccccc}
\cline { 3 - 10 } & \multicolumn{10}{c}{$\phi_{\mathrm{R}} \times 10^{3}$} \\
\hline Solvent & $\lambda_{\text {exc }} / \mathrm{nm}$ & $\mathrm{MeO}$ & $\mathrm{PhO}$ & $\mathrm{Me}$ & $\mathrm{H}$ & $\mathrm{Cl}$ & $\mathrm{COMe}$ & $\mathrm{CN}$ & $\mathrm{NO}_{2}$ \\
\hline Hexane & 254 & $\mathbf{2 6}$ & $\mathbf{4 1}$ & $\mathbf{2 0}$ & $\mathbf{3 7}$ & $\mathbf{4 0}$ & $\mathbf{1 0}$ & $\mathbf{4}$ & Insoluble \\
$\mathrm{MeCN}$ & 254 & 5 & 7 & 6 & 10 & 4 & 1 & 3 & 0.3 \\
$\mathrm{MeOH}$ & 254 & 2 & 2 & 2 & 2 & 2 & 0.4 & 1 & 0.2 \\
\hline $\mathrm{MeCN}$ & 310 & 3 & 2 & 2 & 3 & 3 & 2 & 2 & 0.5 \\
$\mathrm{MeOH}$ & 310 & 0.1 & 0.5 & 1.0 & 1.3 & 1.2 & 1.8 & 1 & 0.5 \\
\hline
\end{tabular}

${ }^{\mathrm{a}}$ Concentration of aryl benzoates: $5.0 \times 10^{-4} \mathrm{M}$. Actinometer: $\mathrm{KI}(0.6 \mathrm{M}), \mathrm{KIO}_{3}(0.1 \mathrm{M})$ and $\mathrm{Na}_{2} \mathrm{~B}_{2} \mathrm{O}_{7} \cdot 10 \mathrm{H}_{2} \mathrm{O}(0.01 \mathrm{M})$ solution in water; $\phi\left(\mathrm{I}_{3}-\right)=0.74 ; \lambda_{\mathrm{exc}}=254 \mathrm{~nm}$. [35] Error: \pm 0.01 .

Bold values indicate the data which are the most significant

These results led to conclude that both families of substituents electron-donor and electron-withdrawing substituents promote a bathochromic shift of the absorption band with respect to benzanilide (4). This dual behavior can be attributed to the significant polarization of the doubly substituted benzene ring. The amide group can behave as a weak electron-donor group when located in para position with respect to the electron-withdrawing substituent groups or as a weak electron-withdrawing group when conjugated with an electron-donor group in para position. Nevertheless, the absolute values of the slopes point out that the amide group tends to act as an electron-donor group. Therefore, in both 
Table 3 Energy (E) and maximum absorption wavelengths $\left(\lambda_{\text {abs }}\right)$ values of the UV-visible lower energy band of 4-substituted benzanilides $(\mathbf{1}-\mathbf{8})$ and 5-substituted-2-aminobenzophenones $(\mathbf{1 a}-\mathbf{8 a})$ in different solvents $\left(5.0 \times 10^{-4} \mathrm{M}\right)^{\mathrm{a}}$

\begin{tabular}{|c|c|c|c|c|c|c|}
\hline & \multicolumn{3}{|c|}{$\lambda_{\mathrm{abs}} / \mathrm{nm}$} & \multicolumn{3}{|c|}{$\mathrm{E} / \mathrm{eV}$} \\
\hline & Hexane & $\mathrm{MeCN}$ & $\mathrm{MeOH}$ & Hexane & $\mathrm{MeCN}$ & $\mathrm{MeOH}$ \\
\hline $\mathrm{MeO}$ & 281 & 276 & 278 & 4.40 & 4.48 & 4.45 \\
\hline $\mathrm{PhO}$ & 273 & 271 & 272 & 4.53 & 4.56 & 4.54 \\
\hline $\mathrm{Me}$ & 272 & 269 & 269 & 4.54 & 4.59 & 4.59 \\
\hline $\mathrm{H}$ & 266 & 264 & 264 & 4.65 & 4.68 & 4.68 \\
\hline $\mathrm{Cl}$ & 270 & 267 & 268 & 4.58 & 4.63 & 4.61 \\
\hline $\mathrm{COMe}$ & 287 & 293 & 296 & 4.31 & 4.22 & 4.18 \\
\hline $\mathrm{CN}$ & 255 & 279 & 278 & 4.85 & 4.43 & 4.45 \\
\hline $\mathrm{NO}_{2}$ & Insoluble & 322 & 318 & ---- & 3.84 & 3.89 \\
\hline & Hexane & $\mathrm{MeCN}$ & $\mathrm{MeOH}$ & Hexane & $\mathrm{MeCN}$ & $\mathrm{MeOH}$ \\
\hline $\mathrm{MeO}$ & 380 & 400 & 401 & 3.25 & 3.09 & 3.08 \\
\hline $\mathrm{PhO}$ & 379 & 390 & 392 & 3.26 & 3.17 & 3.15 \\
\hline $\mathrm{Me}$ & 370 & 375 & 377 & 3.34 & 3.30 & 3.28 \\
\hline $\mathrm{H}$ & 350 & 321 & 335 & 3.53 & 3.85 & 3.69 \\
\hline $\mathrm{Cl}$ & 355 & 363 & 378 & 3.48 & 3.40 & 3.27 \\
\hline COMe & 349 & 350 & 350 & 3.54 & 3.53 & 3.53 \\
\hline $\mathrm{CN}$ & 355 & 358 & 362 & 3.48 & 3.45 & 3.41 \\
\hline
\end{tabular}

${ }^{a}$ Blue data refer to hypsochromic shift while red data refer to bathochromic shift.
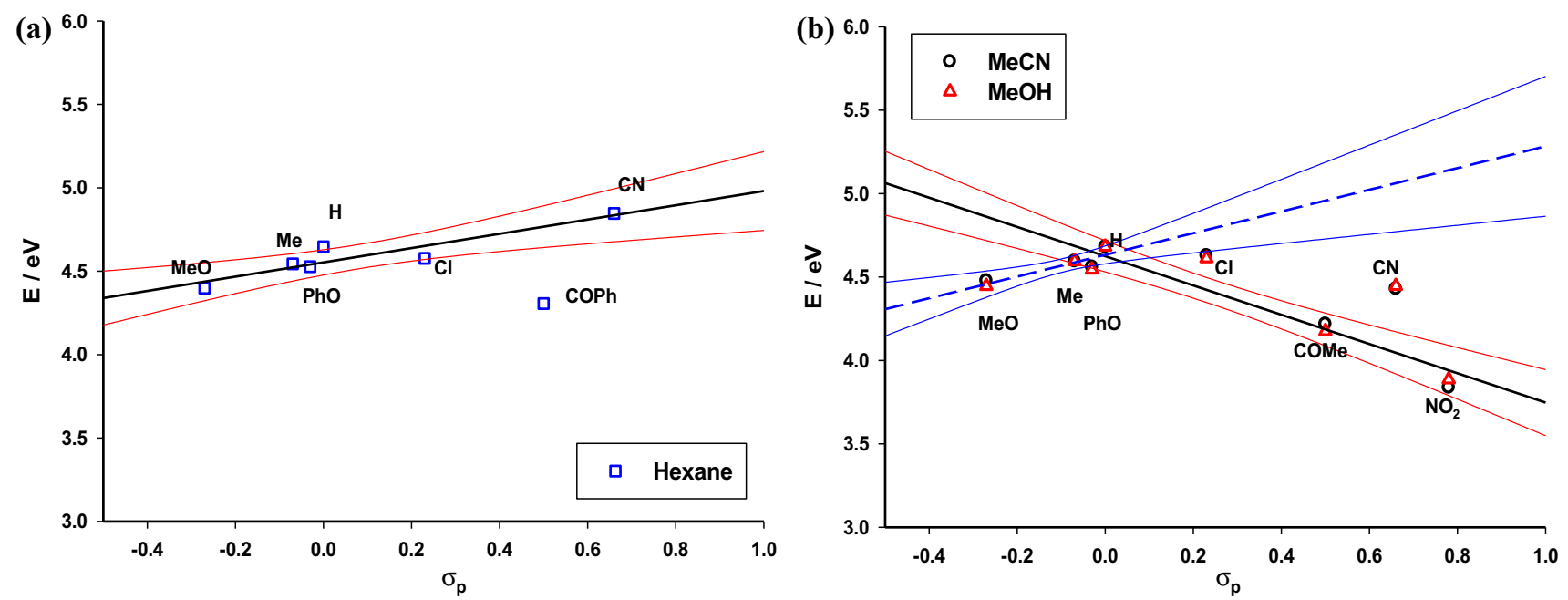

Fig. 3 Hammett Correlation of the UV-visible lower Energy band (E) of 4-substituted benzanilides in: (a) Hexane and (b) methanol and acetonitrile, respectively. Confidence curves (95\%) are reported for both Fig. 2a, b

cases a weak dipole can be developed and polar solvents display a noticeable destabilization of such dipole in the ground state. Conversely, no stabilization of the polarized phenyl ring was observed when hexane, a nonpolar solvent, is used and consequently, a hypsochromic shift was observed with electron-withdrawing substituents.
The new band located between 320 and $450 \mathrm{~nm}$ in the absorption spectra that grows-in with irradiation time (Fig. 2) was assigned to the $n, \pi^{*}$ electronic transition due to the formation of the benzophenone moiety [31]. The maximum absorption wavelength $\left(\pi_{\mathrm{abs}}\right)$ and the energy (E) values of such electronic transition $\left(n, \pi^{*}\right)$ belonging 
to 5-substituted-2-aminobenzophenones are collected in Table 3 . The energies of the lower absorption energy band (E) diminish as the solvent polarity increases, resulting in a bathochromic shift of the $n, \pi^{*}$ band when moving from hexane to methanol. However, no substituent effect was observed on the lower energy band of benzophenones 1a-8a as can be judged from Fig. 4. In fact, the E energies measured in all the solvents studied were correlated with the Hammett meta substituent constants $\sigma_{\mathrm{m}}$ [38] without observing any linear correlation (Fig. 4). This trend suggests that substituents attached to the phenyl ring at meta position do not perturb the polarization of the carbonyl group responsible for the $n, \pi^{*}$ absorption band, both in nonpolar (hexane) and polar (acetonitrile and methanol) solvents.

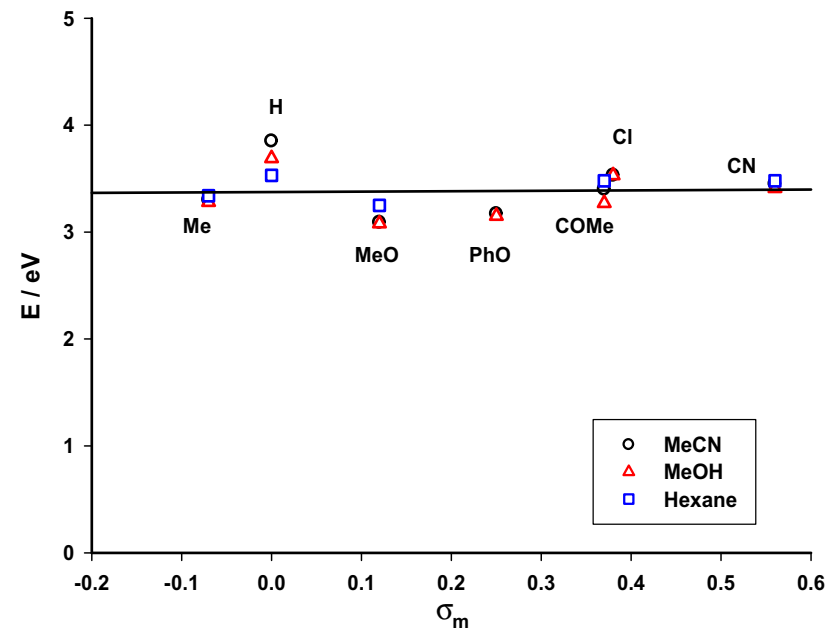

Fig. 4 Hammett Correlation of the UV-visible lower Energy band (E) of 5-substituted 2-aminobenzophenones in hexane, methanol and acetonitrile
We analyzed the substituent and solvent effects on the photoreaction of benzanilides following the relative formation of 2-aminobenzophenones $\mathbf{1 a}-\mathbf{8 a}$, by measuring the relative absorption values $\left(\mathrm{A} / \mathrm{A}_{\infty}\right)$. The concentration of benzanilides 1-8 was $5.0 \times 10^{-5}$ and the absorbance values at the fixed excitation wavelength were ca 0.45 a.u. The relative absorption profiles shown in Fig. 4 were measured in hexane and acetonitrile upon irradiation of the benzanilides at $254 \mathrm{~nm}$, while those relative absorption profiles measured in methanol and in acetonitrile at both $254 \mathrm{~nm}$ and $310 \mathrm{~nm}$ excitation wavelengths are depicted in Figure S9 (see ESI). Comparing the relative absorption profiles measured at $254 \mathrm{~nm}$ in Fig. 5, it was found that the grow-in of 2-aminobenzophenones took place efficiently and resulted to be ten times faster in hexane than in polar solvents such as acetonitrile (compare time scales in Figs. 5(a-b) and methanol (compare time scales in Figure S9). This behavior again suggests the photoreactive excited state being stabilized by polar solvents, favoring competitive radiation and radiationless deactivation pathways over the photochemical reaction pathway. Conversely, the photo-Fries rearrangement reaction proceeds smoothly in hexane because there is no stabilization of the photoreactive excited state and no competition with the deactivation pathways occurs. Furthermore, the relative formation of benzophenones $\mathbf{6 a}$ and $\mathbf{8 a}$ was found to proceed with rate constants slower than that observed for the other benzophenone derivatives (Figs. 5(b) and S9(a)). The competitive population of the triplet excited states of benzophenones $\mathbf{6 a}$ and $8 \mathbf{a}$ that occurs efficiently due to the spin-orbit coupling process promoted by the carbonyl and the nitro groups attached to the phenyl moiety accounts for the slow rate constants [30].

The substituent effect on the photoreaction of 4-substituted benzanilides was also studied quantitatively in terms of
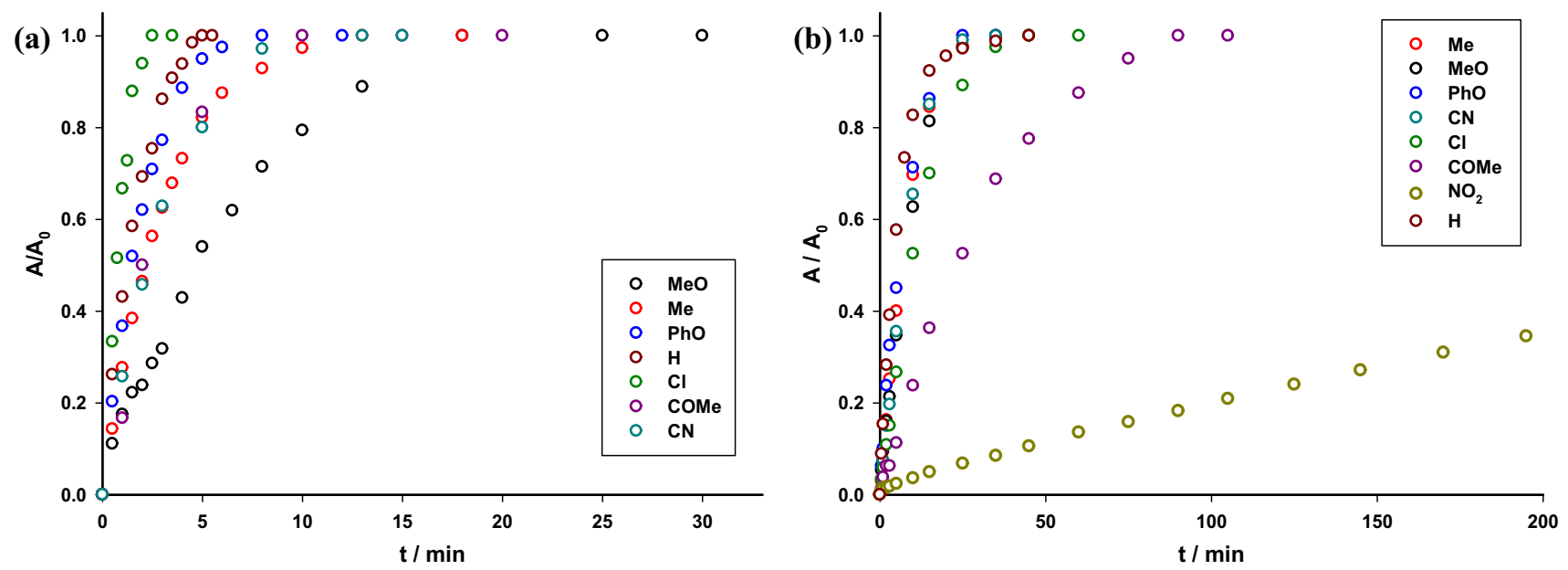

Fig. 5 Relative formation (A/A $\mathrm{A}_{\infty}$ ) profiles of 5-substituted 2-amino-benzophenone in (a) hexane and (b) acetonitrile upon irradiation with light of $254 \mathrm{~nm}$. The concentration of benzanilides $\mathbf{1}-\mathbf{8}$ is $5.0 \times 10^{-5} \mathrm{M}$ 
the Hammett linear free energy correlations [36, 37] according to the Eq. (1)

$\log [k(R) / k(H)]=\rho . \sigma_{p}$

where $k(\mathrm{R})$ and $k(\mathrm{H})$ are the rate constants of p-substituted benzanilides and benzanilide, respectively, $\rho$ is the slope that provides the magnitude of the substituent effect and $\sigma_{\mathrm{p}}$ is the Hammett substituent constants [38]. The rate constants $(k(\mathrm{R})$ and $k(\mathrm{H}))$ were easily calculated by applying a first-order kinetic procedure to the relative formation profiles of the benzophenone derivative. Then, the corresponding consumption rate constants were obtained from the slope of the linear correlation between $\ln \left(\mathrm{C} / \mathrm{C}_{0}\right)$ and reaction time $(t)$ (Figure $\mathrm{S} 10$ in Supporting Information). Likewise, the consumption rate constants were obtained from the slope of the linear correlation between $\ln \left(1-\left(\mathrm{C} / \mathrm{C}_{\infty}\right)\right)$ and reaction time $(t)$ (see Figure S10 in Supporting Information). With the rate constants $(k)$ in hands, the Hammett linear correlation plots were constructed and are depicted in Fig. 6.

As is apparent from the data shown in Fig. 5(a) a nice Hammett linear correlation can be observed when the compounds where excited at $254 \mathrm{~nm}$ in polar solvent. A $\rho$ value of $-0.59\left(r^{2}>0.95\right)$ was obtained after linear regression fitting. The magnitude of the $\rho$ value refers to a modest substituent effect on the photoreaction of 4-substituted benzanilides, whereas the negative sign denotes that electronwithdrawing substituents slow down the rate of the photoreaction. In contrast, electron-donor substituents operate oppositely. A distinct trend was observed when the Hammett correlation was attempted in nonpolar solvent such as hexane. In fact, we obtained a bell-shape, suggesting that

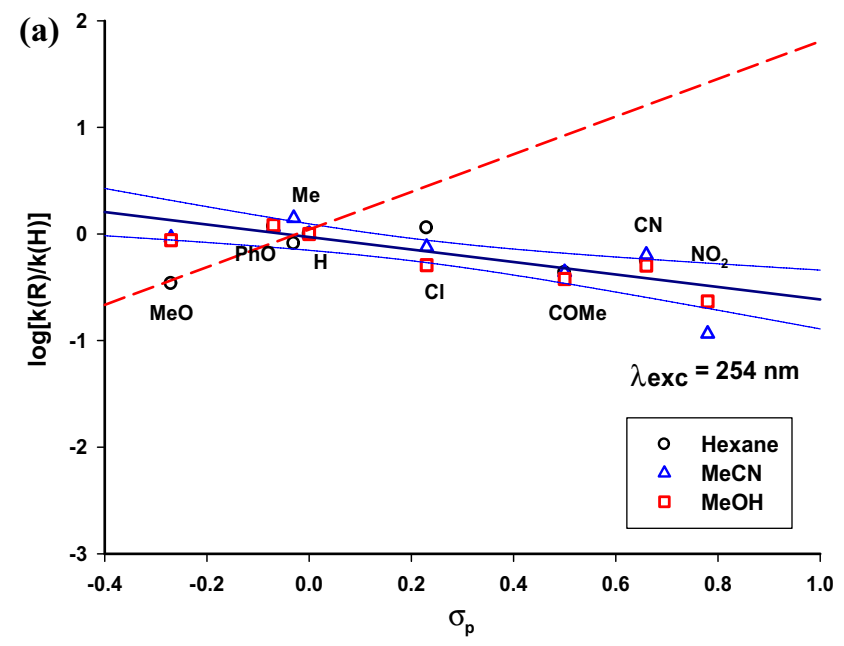

Fig. 6 (a) Hammett linear relationship of the consumption rate constants of 4-substituted benzanilides with the substituent constants $\left(\sigma_{p}\right)$ in hexane, acetonitrile and methanol upon irradiation with light of $254 \mathrm{~nm}$. (b) Hammett linear relationship of the formation rate con- electron-donor and electron-withdrawing substituents deaccelerate the photoreaction. Thus, for the case of electrondonor groups such as methoxy, phenoxy and methyl a $\rho_{1}$ value of $+1.77\left(R^{2}>0.90\right)$ was obtained, indicating that the rate constants of these substituted benzanilides are lower than that of benzanilide (4), whereas a $\rho_{2}$ value of -0.59 was achieved for electron-withdrawing substituents such as chloride, nitrile, acetyl and nitro). In the last case, the slope suggests again that electron-acceptor groups display lower rate constants than benzanilide (4). Furthermore, the $\rho_{1} / \rho_{2}$ ratio is $3: 1$, meaning that the electron-donor substituents affect the photoreaction rate constants much more than electron-acceptor ones. This peculiar behavior could be probed checking computationally the different substituent effects on the stabilization of the reagent of the photo-Fries reaction $(1-8)$ vs. the cyclohexadienone intermediate (1a-8a). Using an isodesmic reaction (see Figure S22 and S23) we could demonstrate that both electron-withdrawing and electrondonating groups stabilize more the benzanilide compared to the respective cyclohexadienone. However, no Hammett linear correlation was experimentally observed when the photoreaction of benzanilides (1-8) was performed upon irradiation at $310 \mathrm{~nm}$ in benzene, acetonitrile and methanol (see Figure S11). As an example, Scheme 2(a) depicts the induced polarization in benzanilides through resonance effect when the $\mathrm{X}$ group is an electron-withdrawing substituent located in para position with respect to the $\mathrm{PhC}(\mathrm{O})$ $\mathrm{NH}-$, acting as a moderate electron-donor group. Thence, the excited state of these benzanilides is modestly stabilized and, consequently, the photo-Fries reaction proceeds slowly.

Figure 5(b) also shows a Hammett linear correlation when the formation rate constants of benzophenone derivatives

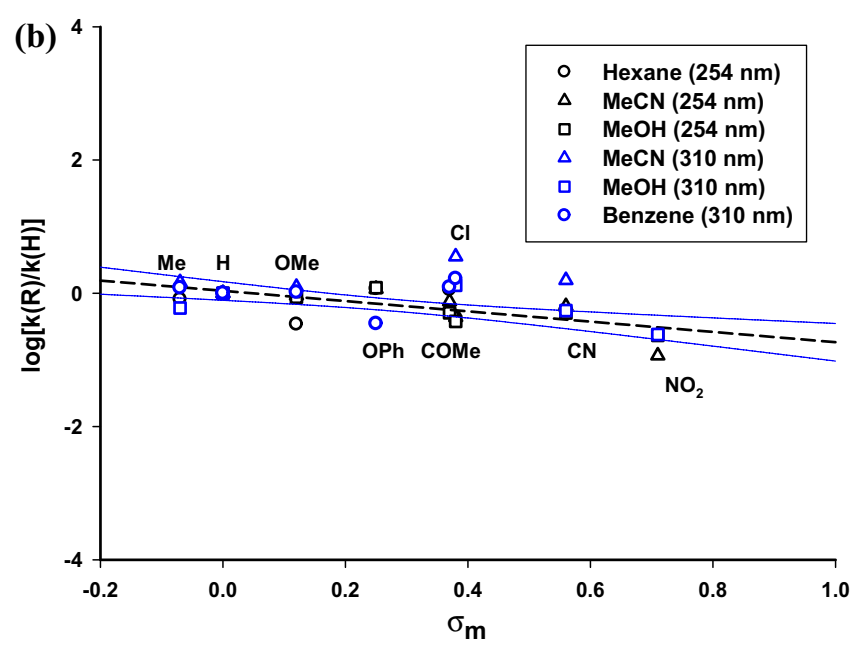

stants of 5-substituted 2-aminobenzophenones with the substituent constants $\left(\sigma_{\mathrm{m}}\right)$ in benzene, acetonitrile and methanol upon irradiation with light of $254 \mathrm{~nm}$ and $310 \mathrm{~nm}$, respectively. Confidence curves (95\%) are reported for both Fig. 6a, b 
(1a-8a) were plotted against the meta Hammett substituent constants $\left(\sigma_{\mathrm{m}}\right)$ according to Eq. 1 . The formation rate constants $(k)$ were easily calculated from the relative absorption profiles by plotting the $\ln \left(1-\mathrm{A}_{\text {rel }}\right)$ vs. time (see Figure S10) in different reaction solvents and at 254 and $310 \mathrm{~nm}$, respectively. The linear Hammett correlation provided a $\rho$ value of $-0.77\left(r^{2}>0.95\right)$ and again the magnitude of $\rho$ reflects a moderate substituent effect on the formation of the benzophenone derivatives while the negative sign leads to conclude that electron-donor substituents accelerate the formation of the benzophenones (1a-8a). Scheme 2(b) depicts the resonance structure of intermediate cyclohexadienone, underlying the direct interaction of substituent $\mathrm{X}$ with the hexadienone moiety. In fact, electron-withdrawing substituents stabilize the cyclohexadienone intermediate, slowing down the rate of [1;3]-hydrogen atom migration involved during the re-aromatization pathway of such intermediate to provide the benzophenone derivatives. Conversely, electron-donor substituents accelerate the rate of [1;3]-hydrogen atom migration promoting the formation of benzophenones 1a-8a.

The solvent effect was also analyzed on the photoreaction of 4-substituted benzanilides 1-8 irradiating the solutions at both excitation wavelengths, i.e., $254 \mathrm{~nm}$ and $310 \mathrm{~nm}$.
Figure 6 depicts the profiles of the relative formation $\left(\mathrm{A}_{\text {rel }}\right)$ of benzophenones $\mathbf{2 a}$ and $\mathbf{4 a}$ in different solvents recorded at both excitation wavelengths. Similar formation profiles were also recorded for benzophenones $1 \mathbf{1}, \mathbf{6} \mathbf{a}$ and $\mathbf{7 a}$ in polar and nonpolar solvents at 254 and $310 \mathrm{~nm}$ and are shown in Figure S18 (see ESI). As can be seen in Fig. 7, the relative formation profiles of benzophenones $\mathbf{2 a}$ and $4 \mathbf{a}$ measured at $254 \mathrm{~nm}$ and $310 \mathrm{~nm}$ depend on the polarity of the reaction solvent. In fact, the formation rate slows down as the polarity of the solvent increases on moving from hexane (benzene) to methanol. Likewise, a similar solvent effect was also observed for the rate of formation of the other benzophenones at both irradiation wavelengths (see Figure S18 in ESI).

Based on these qualitative results the solvent effect on the photoreaction was then quantified using the Reichardt's solvent polarity parameter $\mathrm{E}_{\mathrm{T}}(30)$ [39]. The consumption rate constants $(k)$ of benzanilides 1-8 were obtained from the slope of the linear regression fitting applied on the plots of $\ln \left(\mathrm{C} / \mathrm{C}_{0}\right)$ vs. time (see Figures S13-S17 in ESI). Then, a linear correlation between the reaction rate constant $k$ and the solvent parameter $\mathrm{E}_{\mathrm{T}}(30)$ can be described according to Eq. (2) [39],
Scheme 2 Substituent effects on (a) 4-substituted benzanilides and (b) cyclohexadienone intermediate (a)

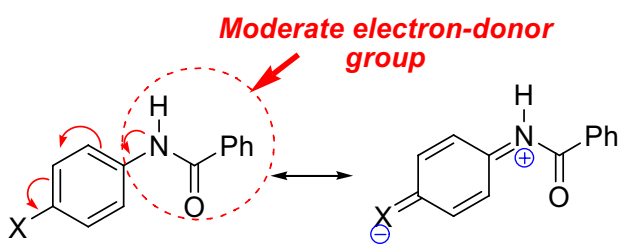

$X:$ electron-withdrawing substituents.
Polarized molecule (b)

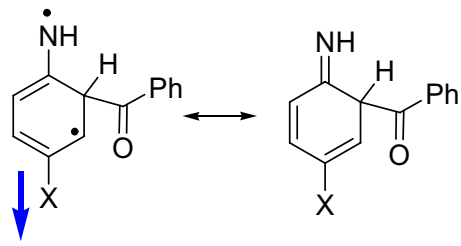

Electron-withdrawing substituents stabilized the cyclohexadienone.
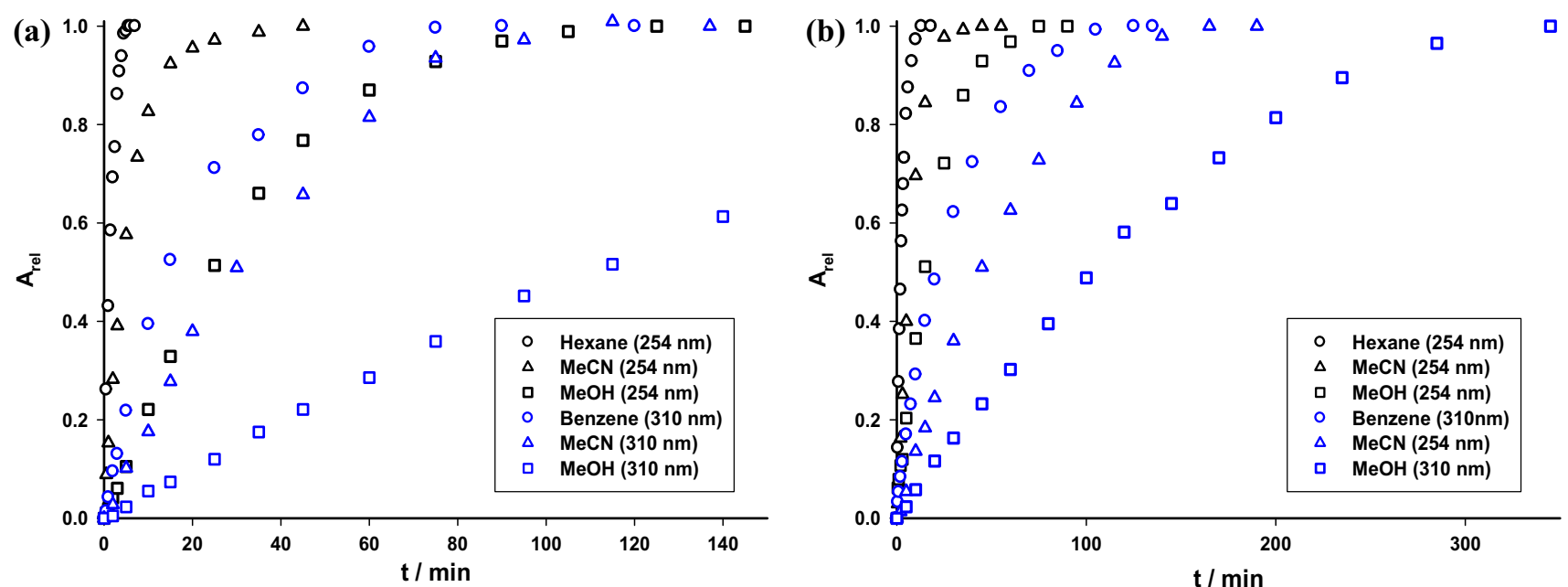

Fig. 7 Relative formation (A/A ${ }_{\infty}$ ) profiles of $(\mathbf{a})$ benzophenone $4 \mathbf{a}$ and $(\mathbf{b})$ benzophenone $2 \mathbf{a}$ in different solvents recorded upon irradiation with light of $254 \mathrm{~nm}$ and $310 \mathrm{~nm}$ 
$\operatorname{In}(\mathrm{k})=\mathrm{m} \cdot \mathrm{E}_{\mathrm{T}}(30)+\mathrm{constant}$

where $m$ is the slope of the linear correlation that provides the sensitivity of the photoreaction on changing the solvent polarity. Figure 8 shows the plots of $\ln (k) v \mathrm{E}_{\mathrm{T}}(30)$ and the linear regression fittings for the cases of 4-methoxybenzanilide (1) and 4-acetylbenzanilide (6), respectively. The linear correlations obtained for benzanilides 1, 6 and 7 are shown in Figure S19 (see ESI). As is apparent from Fig. 8 good linear correlations were obtained when the irradiation of benzanilides were carried out at 254 and $310 \mathrm{~nm}$ demonstrating that the solvent influences the photoreaction. Application of linear regression fittings to the plots shown in Fig. 8 and Figure S19 provided the slopes $m$ according to Eq. (2), these values are collected in Table 4.

The slope $m$ values collected in the table which were obtained at $254 \mathrm{~nm}$ as well as at $310 \mathrm{~nm}$ and for each p-substituted benzanilides are similar, suggesting that the solvent effect is independent from the excitation wavelength. Furthermore, the magnitude of the slope $m$ indicates that the photoreaction rate constants $(k)$ suffer the variation of the solvent polarity to some extent, whereas the sign of the slope reveals that nonpolar solvents such as hexane and benzene accelerate the photoreaction rate constants and polar solvents like acetonitrile and methanol operate oppositely. The fact that polar solvents slow down the photoreaction rate constants was attributed to the noticeable stabilization of the singlet excited state of the 4-substituted benzanilides which is the photo reactive state responsible for the homolytic fragmentation of the amide group. Instead, in nonpolar media the homolytic fragmentation is favored and the photo-Fries rearrangement reaction proceeds efficiently (Fig. 8 8).

\section{Discussion}

As it was described above, the photo-Fries rearrangement reaction of 4-substituted benzanilides $\mathbf{1}-\mathbf{8}$ proceeded smoothly upon direct irradiation with light of $254 \mathrm{~nm}$ and $310 \mathrm{~nm}$ (see Fig. 1, Table 1). The benzanilides were photoconverted with quantum yields $\left(\phi_{R}\right)$ of 0.001 to 0.02 depending on the light source (Table 2), providing 5 -substituted2-amino-benzophenones 1a-8a as the main photoproducts. During the irradiation it was found that the photoreactivity of benzanilides shows a noticeable dependence on the solvent polarity and the nature of the substituents (Figs. 5, 7). The proposed reaction mechanism for the photorearrangement of benzanilides 1-8 is depicted in Scheme 3 and it was supported by the results obtained under steady-state conditions. Thus, direct irradiation of benzanilides with light of 254 (or 310) nm efficiently provided the singlet state, which is the photoreactive state, as reported in the literature [1-3]. Two pathways are involved in the deactivation of the singlet state, (i) homolytic fragmentation of the $\mathrm{C}-\mathrm{NH}$ bond (path (a); Scheme 3) affording two radical species in the solvent cage, viz. aryl ammoniumyl $\mathbf{A}(\mathrm{ArNH} \bullet)$ and benzoyl $\mathbf{B}(\mathrm{PhCO} \bullet)$ radicals, that evolves to 5-substituted-2-aminobenzophenones (1a-8a) and 4-substituted anilines (2a-8b) and (ii) competitive photophysical deactivation of the singlet state in terms of internal conversion and fluorescence emission pathways $\left(k_{\mathrm{d}}\right.$; Scheme 3$)$ that give the benzanilides in their ground state. In the case of amides $\mathbf{6}$ and $\mathbf{8}$, which bear a carbonyl group and a nitro group, respectively, the intersystem crossing pathway must be considered as a process involved in the physical deactivation pathway estimating a $\phi_{\mathrm{T}}$ value around 0.50 [30-32]. Furthermore, when the reaction solvent is a polar solvent such as acetonitrile and methanol it is known that a twisted amide bond (TICT states) excited state is formed from the singlet state of benzanilides (path (b) in Scheme 3) [18-27]. Then, stabilization of TICT excited state by polar solvents favors the deactivation of such

Table 4 Slopes from the linear relationship between $\ln (k)$ and Reichardt's solvent parameter $\left(\mathrm{E}_{\mathrm{T}}(30)\right)$ of some 4-substituted benzanilides measured at $254 \mathrm{~nm}$ and $310 \mathrm{~nm}$

\section{Slope $m$}

\begin{tabular}{|c|c|c|c|c|c|c|}
\hline Benzanilides & & $\mathrm{MeO}(\mathbf{1})$ & $\operatorname{Me}(2)$ & $\mathrm{H}(4)$ & $\operatorname{MeCO}(\mathbf{6})$ & $\mathrm{CN}(7)$ \\
\hline \multirow[b]{2}{*}{$\lambda_{\text {exc }} / \mathbf{n m}$} & 254 & -0.058 & -0.073 & -0.121 & -0.091 & -0.089 \\
\hline & 310 & -0.042 & -0.076 & -0.094 & -0.046 & -0.119 \\
\hline
\end{tabular}



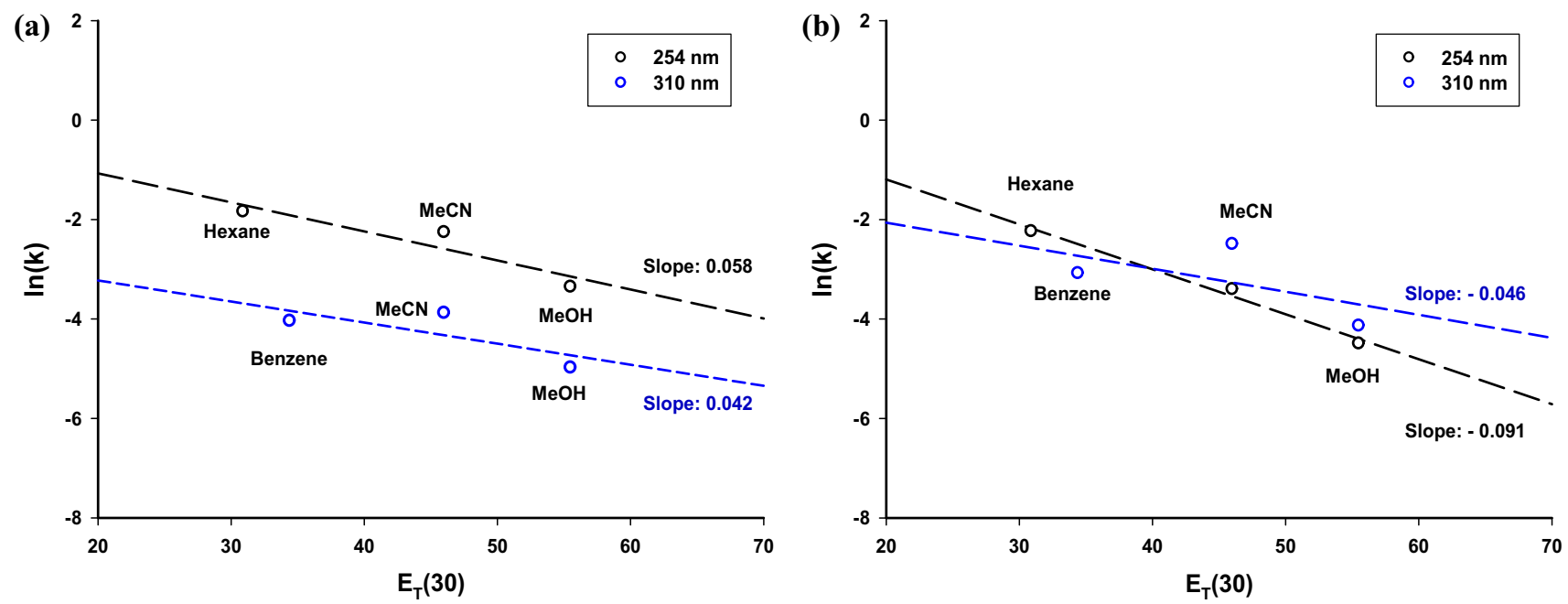

Fig. 8 Linear relationships of reaction rate constants $(\ln (k))$ of (a) 4-methoxybenzanilide (1) and (b) 4-acetylbezanilide (6) with the Reichardt's solvent parameter $\left(\mathrm{E}_{\mathrm{T}}(30)\right)$ at $254 \mathrm{~nm}$ and $310 \mathrm{~nm}$

state through $k_{d}^{\prime}$ pathway (path (b) in Scheme 3) preventing in part the photochemical reaction as can be judged from the quantum yields in polar solvents (Table 2). In fact, not all the singlet excited state of benzanilides shifts to TICT states in polar solvents and consequently, the homolytic fragmentation of benzanilides 1a-8a also proceeds smoothly in such solvents (path (a) in Scheme 3).

The homolytic fragmentation of the amide group led to the formation of two radical species within the solvent cage, i.e., radicals $\mathbf{A}$ and $\mathbf{B}$, which are consumed efficiently through two competitive pathways, the in-cage coupling (path $(\boldsymbol{c}))$ and the out-of-cage escape (path $(\boldsymbol{e}))$. The incage ortho-coupling of radicals $\mathbf{A}$ and $\mathbf{B}$ led to 5-substituted 2-benzoylcyclohexadienone intermediates $\mathbf{C}$ that, in turn, evolved to the 5-substituted-2-aminobenzophenone derivatives (1a-8a) through an efficient coupled intramolecular [1;3]-hydrogen atom transfer ([1;3]-HAT) and re-aromatization according to path (d) in Scheme 3. The sequence involving path (a), path (c) and path (d) is suggested to be the main reaction pathway, because the benzophenones are the main photoproducts formed upon direct irradiation of benzanilides 1-8 (see Table 1). The bimolecular rate constant associated with path $(\boldsymbol{c})$ is expected to display values of $10^{9}-10^{10} \mathrm{M}^{-1} \mathrm{~s}^{-1}$ as it was found for the case of aryl benzoates [34]. The formation of 4-substituted anilines (2b-8b) resulted from the out-cage escape of radical $\mathbf{A}$ into the bulk that can abstract a hydrogen atom from the reaction solvent (path (e) in Scheme 3). Similarly, radical B proceeds to afford benzaldehyde.

The substitution effect on the energy values (E) at the absorption maxima of 4-substituted benzanilides and the 5-substituted-2-aminobenzophenones is interesting (Table 3). The Hammett correlations observed for benzanilides depend on the solvent. A hypsochromic shift of the absorption maximum is noticed with increasing Hammett $\sigma_{\mathrm{p}}$ values when the data were measured in hexane and a $\rho$ value of +0.39 was obtained [Fig. 2(a)]. However, a bell-shape trend was observed in acetonitrile and methanol and two $\rho$ values were fitted: $\rho=+0.65$ and $\rho=-0.88$ [see Fig. 2(b)]. This notable behavior promotes a red shift of the absorption band, which is independent of the nature of the substituent group with respect to benzanilide (4). Likewise, the solvent and substituent effects were also analyzed on the benzophenones derivatives. Indeed, the $\mathrm{E}$ values diminish as the solvent polarity increases, showing a bathochromic shift of the $n, \pi^{*}$ band when moving from hexane to methanol. However, no substituent effect using $\sigma_{\mathrm{m}}$ was observed on the lower energy band of benzophenones 1a-8a (Fig. 3) meaning that the substituents attached to the phenyl ring at meta position do not perturb the polarization of the carbonyl group which is responsible of the $n, \pi^{*}$ absorption band.

On the other hand, the effects of the substituent and the solvent polarity on the photoreaction of 4-substituted benzanilides were also studied quantitatively and it was found that both effects determine the reactivity of benzanilides as well as intermediate $\mathbf{C}$. In fact, the Hammett linear correlation of consumption rate constants $(k(\mathrm{R}))$ of p-substituted benzanilides leads to $\rho=-0.59$ [Fig. 5(a)] when the photoreaction was carried out at $254 \mathrm{~nm}$ in polar solvents. Although the magnitude of $\rho$ refers to a modest substituent effect on the photoreaction, the negative sign denotes that electron-withdrawing substituents slow down the rate of homolytic fragmentation (path (a) in Scheme 3) while electron-donor substituents operate in an opposite way. We rationalized this finding suggesting that polarization in benzanilides through resonance effect, due to the 


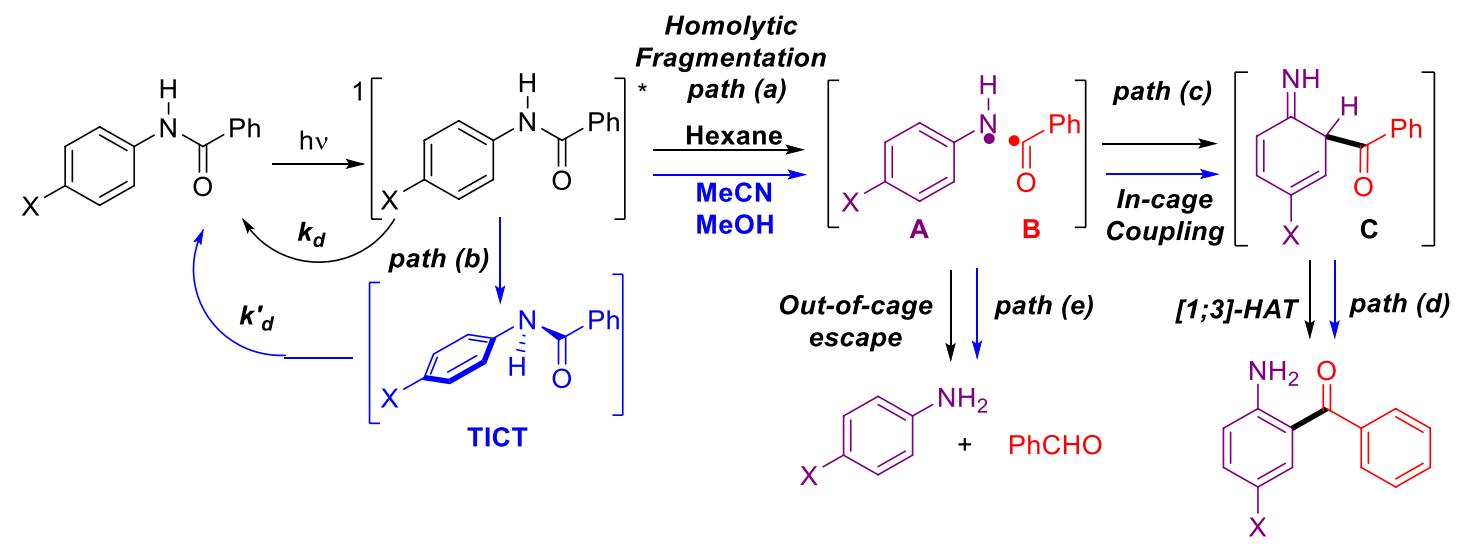

Scheme 3 Proposed reaction mechanism of the photo-Fries rearrangement of benzanilides 1-8

location of electron-withdrawing substituents in para position to the $\mathrm{PhC}(\mathrm{O}) \mathrm{NH}-$, a moderate electron-donor group (see Scheme 2). However, in nonpolar solvents a bell-shape behavior was observed and two slopes were obtained, viz. $\rho_{1}=+1.77$ and $\rho_{2}=-059$. Both kinds of substituents slow down the reaction rate compared to the rate constant of benzanilide (4). Furthermore, the $\rho_{1} / \rho_{2}$ ratio was found to be $3: 1$, indicating that the slowing down of the photoreaction is higher with electron-donor groups than electron-withdrawing substituents. Likewise, the substituent effect on the rate of formation $(k(\mathrm{R}))$ of 5-substituted-2-aminobenzanilides was also analyzed and a $\rho$ value of -0.77 was obtained in all the solvents studied and at both excitation wavelengths [Fig. 5(b)]. Indeed, the negative sign of the $\rho$ value again accounts for the slowdown of the rate constant when the para substituent is an electron-withdrawing group, while a noticeable acceleration of the rate of formation of benzophenones is clearly observed with electron-donor substituents (see Fig. 5(b)). Therefore, electron-withdrawing groups stabilize the 2-benzoylcyclohexadienone intermediate $\mathbf{C}$ through direct resonance effect (see Scheme 2) slowing down the intramolecular [1;3]-hydrogen atom transfer rate constant of formation of the corresponding benzophenones (path (d) in Scheme 3).

The solvent effect on the photoreaction was also analyzed quantitatively using the Reichardt's solvent polarity parameter $\mathrm{E}_{\mathrm{T}}(30)$. Nicely linear correlations were found when the consumption rate constants as $\ln (k)$ of benzanilides 1-8 were plotted against the $\mathrm{E}_{\mathrm{T}}(30)$ Reichardt parameter (see Figs. 7 and S19), providing $m$ values which were similar at both excitation wavelengths (254 or $310 \mathrm{~nm}$ ) (see Table 4). The magnitude of $m$ indicates that the photoreaction rate constants $(k)$ depends on the solvent polarity and the negative sign of $m$ reveals that nonpolar solvents (hexane and benzene) accelerate the photoreaction rate constants whereas polar solvents operate oppositely. This phenomenon was attributed to the stabilization of the photoreactive singlet state of benzanilides responsible for the homolytic fragmentation of the amide group (path (a) in Scheme 3). The photo reactive singlet state is less stabilized in nonpolar media and the homolytic fragmentation is favored, bringing efficiently the photo-Fries reaction.

\section{Conclusion}

The photo-Fries rearrangement of 4-substituted benzanilides (1-8) examined in this paper takes place smoothly in nonpolar solvents such as cyclohexane and benzene and polar solvents (acetonitrile and methanol) at both irradiation wavelengths, i.e. $254 \mathrm{~nm}$ and $310 \mathrm{~nm}$. Indeed, 5-substituted2-aminobenzophenones $\mathbf{1 a - 8 a}$ were obtained in good yields as the main photoproducts, along with 4-substituted anilines detected in very low yields. The reaction quantum yields $\left(\phi_{\mathrm{R}}\right)$ of benzanilides $\mathbf{1}-\mathbf{8}$ suggest that the photoreaction proceeds efficiently when hexane is the solvent whereas in polar solvents the $\phi_{\mathrm{R}}$ values diminish by one order of magnitude, reflecting a slowdown of the photoreaction. Polar solvents possibly stabilizes the twisted amide bond (TICT) excited state favoring the deactivation of such state through fluorescence emission and radiationless pathways and preventing the photochemical reaction.

No substituent and solvent effects on the low absorption band energy (E) values of 5-substituted-2-aminobenzophenones (1a-8a) was observed when moving from cyclohexane to methanol as well as when Hammett substituent correlation was performed with the substituent constant $\sigma_{\mathrm{m}}$ parameter. However, the analysis of the $E$ values of 4-substituted benzanilides clearly displayed noticeable solvent and substituent effects. In fact, the Hammett correlation on the $E$ values measured in hexane showed a hypsochromic shift of the absorption wavelength as the electron-withdrawing character of the substituent increases. Conversely, a bathochromic effect of the absorption band measured in polar solvents was 
observed as the electron-donor character of the substituent is increased.

The Hammett linear relationship on the consumption of benzanilides and formation of benzophenones rate constants $(k(\mathrm{R}))$ was also analyzed. A modest role of the substituents on the homolytic fragmentation of the C-N bond of the amide group as well as on the formation of the benzophenones was observed in all the solvents studied at both excitation wavelengths ( $254 \mathrm{~nm}$ and $310 \mathrm{~nm})$. In fact, a $\rho$ value of -0.59 obtained for the consumption of the benzanilides indicated that electron-donor substituents accelerate the homolytic fragmentation of the amide group. A similar substituent effect was observed for the formation of benzophenone derivatives because 2-benzoylcyclohexadienone intermediates were stabilized by the electron-donor substituents, as can be judged from the $\rho$ value of -0.77 . This kinetic behavior was observed at 254 and $310 \mathrm{~nm}$ in all the solvents studied.

The photo-Fries rearrangement reaction of benzanilides was found to depend on the solvent polarity. In fact, the rate of consumption of benzanilides as $\ln (k)$ was observed to correlate nicely with the Reichardt's solvent polarity $\mathrm{E}_{\mathrm{T}}(30)$. The negative value of the slopes $m$ suggested that nonpolar solvents such as hexane or benzene accelerated the photoreaction while more polar solvents such as acetonitrile and methanol operate in the opposite way.

Finally, the obtained results showed how the reaction solvent and the substituents' electronic effects affect the photoreaction and the formation of the main photoproduct, viz. the 5 -substituted-2-aminobenzophenone derivatives, in yields up to $60 \%$ when nonpolar solvents were used.

\section{Experimental section}

\subsection{Material and equipment}

4-Substituted anilines, benzanilide, 2-aminobenzophenone, 4-aminobenzophenone, 5-nitro-2-aminobenzophenone, 5-methyl-2-aminobenzophenone, 5-chloro-2-aminobenzophenone, 5-methoxy-2-aminobenzophenone, benzoyl chloride and pyridine were obtained from commercial sources. Spectroscopic grade solvents were used as received. Pyridine was distilled and stored over $\mathrm{KOH}$ pellets. Melting Points were determined with a Fisher-Johns apparatus and are not corrected. ${ }^{1} \mathrm{H}$ and ${ }^{13} \mathrm{C}$ NMR spectra were recorded in $\mathrm{CDCl}_{3}$ on a $500 \mathrm{MHz}$ spectrometer; chemical shifts $(\delta)$ are reported in part per million ( $\mathrm{ppm}$ ), relative to signal of tetramethylsilane, used as internal standard. Coupling constant $(\mathrm{J})$ values are given in $\mathrm{Hz}$. The measurements were carried out using standard pulse sequences. GC analysis was carried out on a Hewlett Packard 5890 gas chromatograph using an Ultra 2 capillary chromatographic column. The chromatograms were recorded with the following program: initial temperature: $100{ }^{\circ} \mathrm{C}, 2 \mathrm{~min}$; gradient rate: $10^{\circ} \mathrm{Cmin}^{-1}$; final temperature: $250^{\circ} \mathrm{C}, 10 \mathrm{~min}$. The UV-visible spectra were measured with a Shimadzu UV-1203 spectrophotometer using twofaced stoppered quartz cuvettes $(1 \mathrm{~mm} \times 1 \mathrm{~mm})$ at $298 \mathrm{~K}$.

\subsection{Synthesis of 4-substituted benzanilides 1-8}

\subsubsection{General procedure}

To a solution of the substituted anilines $(0.010 \mathrm{~mol})$ in pyridine $(10 \mathrm{~mL})$ cooled in an ice-bath, benzoyl chloride (0.012 mol) was added dropwise in 10 min under stirring. Subsequently, the reaction mixture was kept under stirring for $60 \mathrm{~min}$. After total consumption of the starting material was confirmed by TLC, the reaction mixture was extracted with dichloromethane $(10 \mathrm{~mL})$ and washed with a solution of diluted $\mathrm{HCl}(10 \mathrm{~mL})$. The organic phase was then washed with water, dried on $\mathrm{Na}_{2} \mathrm{SO}_{4}$, filtrated and evaporated under pressure. The 4-substituted benzanilides were purified from the solid residue by recrystallization using ethanol - water mixtures giving the corresponding benzanilides in excellent yields (>90\%). The 4 -substituted benzanilides were characterized comparing the melting points (m.p.) and spectroscopic data $\left({ }^{1} \mathrm{H}-\mathrm{NMR}\right.$ and $\left.{ }^{13} \mathrm{C}-\mathrm{NMR}\right)$ with the ones reported in the literature (see ESI).

\subsection{Photoirradiations}

\subsubsection{General procedure}

Photoirradiations of 4-substituted benzanilides in organic solvents. A stock solution of a given benzanilide (1-8, $0.1 \mathrm{mmol}$ in $200 \mathrm{~mL}$ solvent) was placed in a stoppered Erlenmeyer quartz flask and degassed with argon for $30 \mathrm{~min}$. The flask was placed in a home made optical bench able to switch between a four or eigth lamps irradiation setup. The solution was stirred during the entire irradiation. Irradiations with $\lambda_{\text {exc }}=254 \mathrm{~nm}$ were carried with four germicide lamps (Philips, each of 20 Watts). The reaction progress was monitored by TLC [eluent: hexane-ethyl acetate (8: 2 $\mathrm{v} / \mathrm{v}$ ); spots were visualized with UV light (254 and $366 \mathrm{~nm}$ )] and by GC analysis (Ultra 2 capillary column, vide supra). When the conversion of the starting material was higher than $30 \%$, the photolyzed solution was carefully evaporated to dryness under reduced pressure. The yellowish solid residue obtained was dissolved in chloroform- $\mathrm{d}_{3}$ and the ${ }^{1} \mathrm{H}-\mathrm{NMR}$ $(500 \mathrm{MHz})$ were recorded. The spectra are collected in the ESI. 


\subsubsection{Computational analysis}

All the structures were pre-screened using the CREST driver in the xTB software [40], using the GFN2-xTB level. In this way, the most stable conformers for each structure were picked via the default series of metadynamics and dynamics runs implemented in the driver, and re-optimized at the $\omega \mathrm{B} 97 \mathrm{X}-\mathrm{D} / \mathrm{def} 2-\mathrm{SVP}$ level, modelling the molecule in gas and acetonitrile via the SMD implicit solvent method. The excited state geometries were optimized at the TD- $\omega B$ 97X-D/def2-SVP level. All structures were confirmed to be minima by the absence of imaginary vibrational modes. All the DFT and TD-DFT calculations were carried out via Gaussian 16, Rev. B.01 [41].

Supplementary Information The online version contains supplementary material available at https://doi.org/10.1007/s43630-021-00149-0.

Acknowledgements SMB is a research member of CONICET. MIQ and VL thank CONICET for doctoral scholarships (Doctorate Program).

\section{Declarations}

Conflict of interest On behalf of all authors, the corresponding author states that there is no conflict of interest.

\section{References}

1. Bellus, D. (1976). Photo-Fries rearrangement and related photochemical $[1, \mathrm{j}]-\operatorname{shift}(\mathrm{j}: 3,5,7)$ of carbonyl and sulfonyl groups. Advances in Photochemistry, 8, 109-159.

2. Miranda, M. A., Galindo, F. (2003). Photochemistry of organic molecules in isotropic and anisotropic media. In V. Ramamurthy \& K. S. Schanze (Eds.), Chapter 2. The Photo-Fries rearrangement. (pp. 43 - 131). Marcel Dekker

3. Miranda, M. A., Galindo, F. (2004). CRC handbook of organic photochemistry and photobiology. In W. M. Horspool \& F. Lenci (Eds.), Chapter 42. Photo-fries reaction and related processes. CRC Press LLC

4. Anderson, J. C., \& Reese, C. B. (1960). Photoinduced Fries rearrangement (p. 217). Proc. Chem. Soc.

5. Elad, D. (1963). The photochemical rearrangement of N-acylanilines. Tetrahedron Letters, 14, 873-875.

6. Elad, D., Rao, D. V., \& Steinberg, V. I. (1965). The photoanilide rearrangement. Journal of Organic Chemistry, 30, 3252-3254.

7. Shizuka, H., \& Tanaka, I. (1968). Photochemistry of acetanilide. I. quantum yields of the rearrangement and benzene photosensitized reaction. Bull. Chem. Soc. Jp., 41, 2343-2349.

8. Shizuka, H. (1969). Photochemistry of Acetanilide. II. The primary processes in the photochemical reaction. Bull. Chem. Soc. Jp., 42, 52-57.

9. Carlsson, D. J., Gan, L. H., \& Wiles, D. M. (1975). The photolyses of fully aromatic amides. Canadian Journal of Chemistry, 53, 2337-2344.

10. Park, Y.-T., Do, S.-R., \& Lee, K.-P. (1985). Photochemistry of Benzanilide. I. photocyclization of benzanilides. Journal of the Korean Chemical Society, 29, 426-436.
11. Shizuka, H., Kato, M., Ochiai, T., Matsui, K., \& Morita, T. (1970). The photochemical rearrangements of N-acetyl diphenylamine and $\mathrm{N}$-acetyl carbazole. Bullet Chemistry Social Japenes, 43, 67-74.

12. Bonesi, S. M., \& Erra Balsells, R. (1991). Product study of the photolysis of $\mathrm{N}$-acetyl carbazole in ethanol and dichloromethane solution. Part I. Journal of Photochemistry and Photobiology, A: Chemistry, 56, 55-72.

13. Bonesi, S. M., \& Erra Balsells, R. (1997). Photochemistry of $\mathrm{N}$-acetyl and N-benzoyl carbazoles: photo-Fries rearrangement and photoinduced single electron transfer. Journal of Photochemistry and Photobiology, A: Chemistry, 110, 271-284.

14. Chenevert, R., \& Plante, R. (1983). Photochemical rearrangement of acetanilide, benzanilide, and ethyl phenyl carbonate in the presence of $\beta$-cyclodextrin. Canadian Journal of Chemistry, $61,1092-1095$.

15. Syamaia, M. S., Nageswer Rao, B., \& Ramaurthy, V. (1988). Modification of photochemical reactivity by cyclodextrin complexation: product selectivity in photo-Fries rearrangement. Tetrahedron, 44, 7234-7242.

16. Nasetta, M., Rossi, R., \& Cosa, J. J. (1988). Influence of cyclodextrins on the photo-Fries rearrangement of acetanilide. Canadian Journal of Chemistry, 66, 2794-2798.

17. Iguchi, D., Erra Balsells, R., \& Bonesi, S. M. (2016). PhotoFries rearrangement of aryl acetanmides: regioselectivity induced by the aqueous micellar green environment. Photochemical and Photobiological Sciences, 15, 105-116.

18. Tang, G.-Q., MacInnis, J., \& Kasha, M. (1987). Proton-transfer spectroscopy of benzanilide. The amido-imidol tautomerism. Journal of the American Chemical Society, 109, 2531-2533.

19. Azumaya, I., Kagechika, H., Fujiwara, Y., Itoh, M., Yamaguchi, K., \& Shudo, K. (1991). Twisted intramolecular charge-transfer fluorescence of aromatic amides: conformatiom of the amide bonds in the excited states. Journal of the American Chemical Society, 113, 2833-2838.

20. Lewis, F. D., \& Long, T. M. (1998). Anomalous dual fluorescence of benzanilide. Journal of Physical Chemistry A, 102, 5327-5332.

21. Lewis, F. D., \& Weizhong, L. (1999). Luminiscence of N-arylbenzamides in low-temperature glasses. Journal of Physical Chemistry A, 103, 9678-9686.

22. Lewis, F. D., \& Liu, W. (2002). Temperature- and conformationdependent luminescence of benzanilides. Journal of Physical Chemistry A, 106, 1976-1984.

23. Brozis, M., Heldt, J., \& Heldt, J. R. (1999). Spectroscopic studies of four new derivatives of benzamide. Journal of Photochemistry and Photobiology A: Chemistry, 128, 39-45.

24. Heldt, J., Heldt, J. R., \& Szatan, E. (1999). Luminiscence studies of benzamide derivatives at room and low temperatures. Journal of Photochemistry and Photobiology A: Chemistry, 121, 91-97.

25. Heldt, J., Heldt, J. R., \& Szatan, E. (1999). Steady-state and time-resolved spectroscopic studies of benzanilides. Zeitschrift für Naturforschung A, 54, 495-502.

26. Zhang, X., Wang, C.-J., Liu, L.-H., \& Jiang, Y.-B. (2002). Reversal of the intramolecular charge transfer in p-dimethylamino benzanilides by amido aniline substitution. The Journal of Physical Chemistry B, 106, 12432-12440.

27. Zhang, X., Ma, L-H., Sun, X-Y., Wang, C-J., Wu., F-Y., Li, Z., Jiang, Y-B. (2002) Chemical Journal of. China University, 23, $1701-1703$

28. Zhang, X., Liu, C.-H., Liu, L.-H., Wu, F.-Y., Guo, L., Sun, X.-Y., Wang, C.-J., \& Jiang, Y.-B. (2003). Intramolecular charge transfer with N-benzoylaminonaphthalenes. 1-Aminonaphthalene versus 2-aminonaphthalene as electron donors. Organic and Biomolecular Chemistry, 1, 728-732. 
29. Liu, L.-H., Guo, L., Liu, C.-H., Zhang, X., \& Jiang, Y.-B. (2005). Intramolecular charge transfer with 1-naphthalinides and 2-naphthalinides. Chinese Journal of Chemistry, 23, 857-864.

30. Turro, N. J., Ramamurthy, V., \& Scaiano, J. C. (2010). Modern molecular photochemistry of organic molecules. University Science Books.

31. Bonesi, S. M., Mesaros, M., Cabrerizo, F. M., Ponce, M. A., Bilmes, G., \& Erra-Balsells, R. (2007). The photophysiscs of nitrocarbazoles used as UV-MALDI matrices. Comparative spectroscopic and optoacoustic studies of mono- and dinitrocarbazoles. Chemical Physics Letters, 446, 49-55.

32. Cors, A., Bonesi, S. M., \& Erra-Balsells, R. (2008). Photoreduction of nitroarenes with formic acid in acetonitrile at room temperature. Tetrahedron Letters, 49, 1555-1558.

33. Miranda M. A. (1995) CRC handbook of organic photochemistry and photobiology (Edited by W. Horspool and P. S. Song) pp 570. CRC Press

34. Siano, G., Crespi, S., Mella, M., \& Bonesi, S. M. (2019). Selectivity in the photo-Fries rearrangement of some aryl benzoates in green and sustainable media. Preparative and mechanistic studies. Journal of Organic Chemistry, 84, 4338-4352.

35. Goldstein, S., \& Rabani, J. (2008). The ferrioxalate and iodideiodate actinometers in the UV region. Journal of Photochemistry and Photobiology A: Chemistry, 193, 50-55.

36. Hammett, L. P. (1935). Some relations between reaction rates and equilibrium constants. Chemical Reviews, 17, 125-136.

37. Ewing, D. F. (1978) Correlation analysis in chemistry: recent advances (Edited by N B. Chapman and J. Shorter). Plenum Press
38. Hansch, C., \& Leo, A. (1991). A survey of Hammett substituent constants and resonance and field parameters. Chemical Reviews, 91, 165-195.

39. Reichardt, Ch., Welton, T. (2011). Solvents and solvent effects in organic chemitsry. In Ch. Reichardt \& T. Welton (Eds.), Chapter 7. Empirical parameters of solvent polarity. pp $490-508$. Wiley-VCH Verlag GmbH \& Co. KGaA

40. Bannwarth, C., Caldeweyher, E., Ehlert, S., Hansen, A., Pracht, P., Seibert, J., Spicher, S., \& Grimme, S. (2021). Extended tightbinding quantum chemistry methods. Wiley Interdisciplinary Reviews: Computational Molecular Science, 11(2), e1493.

41. Gaussian 16, Revision B.01, M. J. Frisch, G. W. Trucks, H. B. Schlegel, G. E. Scuseria, M. A. Robb, J. R. Cheeseman, G. Scalmani, V. Barone, G. A. Petersson, H. Nakatsuji, X. Li, M. Caricato, A. V. Marenich, J. Bloino, B. G. Janesko, R. Gomperts, B. Mennucci, H. P. Hratchian, J. V. Ortiz, A. F. Izmaylov, J. L. Sonnenberg, D. Williams-Young, F. Ding, F. Lipparini, F. Egidi, J. Goings, B. Peng, A. Petrone, T. Henderson, D. Ranasinghe, V. G. Zakrzewski, J. Gao, N. Rega, G. Zheng, W. Liang, M. Hada, M. Ehara, K. Toyota, R. Fukuda, J. Hasegawa, M. Ishida, T. Nakajima, Y. Honda, O. Kitao, H. Nakai, T. Vreven, K. Throssell, J. A. Montgomery, Jr., J. E. Peralta, F. Ogliaro, M. J. Bearpark, J. J. Heyd, E. N. Brothers, K. N. Kudin, V. N. Staroverov, T. A. Keith, R. Kobayashi, J. Normand, K. Raghavachari, A. P. Rendell, J. C. Burant, S. S. Iyengar, J. Tomasi, M. Cossi, J. M. Millam, M. Klene, C. Adamo, R. Cammi, J. W. Ochterski, R. L. Martin, K. Morokuma, O. Farkas, J. B. Foresman, and D. J. Fox, Gaussian, Inc., Wallingford CT, (2016) 